\title{
QUALIDADE BROMATOLÓGICA DAS SILAGENS DE CAPIM-ELEFANTE ADITIVADAS COM RASPA DE BATATA ${ }^{1}$
}

\author{
Bromatologic qualities of elephant grass silages added with potato scrapings \\ Adauton Vilela de Rezende ${ }^{2}$, Ricardo Rodrigues ${ }^{3}$, Adauto Ferreira Barcelos ${ }^{4}$, \\ André Oliveira Casali ${ }^{5}$, Alexandre Rocha Valeriano ${ }^{6}$, Lucilene Tavares Medeiros ${ }^{7}$
}

\begin{abstract}
RESUMO
A raspa de batata foi misturada ao capim-elefante (Pennisetum purpureum Schum.) na ensilagem. A colheita do capim-elefante foi realizada manualmente após 80 dias do corte de uniformização a uma altura de $10 \mathrm{~cm}$ da superfície do solo. As misturas capimelefante e raspa de batata foram feitas nas seguintes proporções de matéria verde: 100 e $0 \%$, 93 e 7\%; 86 e 14\%; 79 e $21 \%$; 72 e $28 \%$ de capim e raspa de batata, respectivamente. As plantas foram picadas em partículas de 2,0 a 3,0 cm de tamanho, ensiladas por 30 dias, em silos de "PVC" de dez centímetros de diâmetro e quarenta centímetros de altura. Foram avaliadas as porcentagens de matéria seca (MS), valores de $\mathrm{pH}$, perda de gases, perda de efluentes, proteína bruta (PB), fibra em detergente neutro (FDN), fibra em detergente ácido (FDA) e digestibilidade in vitro da matéria seca (DIVMS), das silagens. O delineamento experimental empregado foi o inteiramente casualizado, com quatro repetições. Concluiu-se que as silagens de capim-elefante com raspa de batata apresentaram maiores porcentagens de MS, PB, valores de pH e DIVMS e menor porcentagem de perda de gases, perda de efluentes, FDN e FDA na matéria seca com o aumento dos níveis de adição.
\end{abstract}

Termos para indexação: Silagens, efluentes, gases.

\section{ABSTRACT}

Potato scrapings were mixed with elephant grass (Pennisetum purpureum, Schum) in silage. Elephant grass was harvested manually on the $80^{\text {th }}$ day after leveling mowing had been done at a height of $10 \mathrm{~cm}$ from the soil surface. The mixtures of elephant grass and potato scrapings were made in the in the following ratios of green matter: $100 \%$ and $0 \% ; 93 \%$ and $7 \% ; 86 \%$ and $14 \% ; 79 \%$ and $21 \%$; and $72 \%$ and $28 \%$ of grass and potato scrapings, respectively. The plants were chopped in 2-3 cm particles and ensiled for 30 days in $10 \mathrm{~cm}$ wide $\mathrm{x} 40 \mathrm{~cm}$ high "PVC" silos. The following variables of the silage were evaluated: percentage of dry matter (DM), pH values, loss of gases, and of efluent, crude protein (CP), neutral detergent fiber (NDF), acid detergent fiber (ADF), and in vitro digestibility of dry matter (IVDDM). The experimental design used was the completely randomized with four repetitions. It was concluded that elephant grass silages added with potato scrapings exhibited higher percentages of $\mathrm{DM}$ and $\mathrm{CP}$, higher values of $\mathrm{pH}$, increase in the IVDDM, and a lower percentage of loss of gases, loss of effluent, NDF and ADF in dry matter with increasing levels of addition.

Index terms: Silages, efluent, gases.

(Recebido em 28 de abril de 2006 e aprovado em 9 de agosto de 2006)

\section{INTRODUÇÃO}

A baixa produtividade das forragens durante o inverno, tem sido um dos fatores mais limitantes para se conseguir boas produtividades dos rebanhos brasileiros. $\mathrm{Na}$ tentativa de reverter este quadro, objetivou-se ao longo dos anos o aperfeiçoamento de novas técnicas de manejo de forragens com o intuito de intensificar os processos produtivos.

O termo batata de "diversa" é usado para qualificar a batata imprópria para o comércio, mas não para o consumo, ou seja, aquele produto que não alcança os padrões de comercialização como tamanho e danos nos tubérculos, devido à colheita e beneficiamento. Segundo informações da Associação dos Bataticultores de Minas Gerais, as perdas nestes processos variam de 15 a $20 \%$ da produção, o que representa, de 124 a 165 mil toneladas de batata podendo ser utilizada na alimentação animal.

Lavezzo (1985) sugeriu que, para a produção de silagem, o capim-elefante deve ser cortado com 50 a 60 dias de desenvolvimento, após o corte de uniformização,

\footnotetext{
${ }^{1}$ Parte da dissertação de Mestrado (Zootecnia) do segundo autor junto à UNIFENAS.

Engenheiro agrônomo, Dr. Professor da UNIFENAS - Campus Universitário - 37130-000 - Alfenas, MG - adauton rezende@unifenas br ${ }^{3}$ Médico Veterinário, mestre em zootecnia pela UNIFENAS - Campus Universitário - 37130-000 - Alfenas, MG - ricardo.vet@ide.com.br

${ }^{4}$ Zootecnista e doutor em zootecnia pela Universidade Federal de Lavras/UFLA - Empresa de Pesquisa Agropecuária de Minas Gerais - Secretaria de Estado de Agricultura Pecuária e Abastecimento - Centro Tecnológico do Sul de Minas - Campus da UFLA - Cx. P. 176 - $37200-000$ - Lavras, MG adauto.barcelos@epamig.ufla.br

${ }^{5}$ Zootecnista e mestre em zootecnia pela Universidade Federal de Viçosa/UFV - 36570-000 - Viçosa, MG - andre.casali@bol.com.br

${ }^{6}$ Engenheiro Agrônomo e Mestrando no Departamento de Zootecnia/DZO - Universidade Federal de Lavras/UFLA - CX. P. 3037 - $37200-000$ Lavras, MG - alexandrerv@nwnet.com.br

ZZootecnista e Doutoranda no Departamento de Zootecnia/DZO - Universidade Federal de Lavras/UFLA - Cx. P. 3037 - $37200-000$ - Lavras, MG lucilene@fesurv.br
} 
quando a planta apresenta melhor valor nutritivo. Contudo, verificou-se que o teor de matéria seca da planta nesta idade é muito baixo, 15 a $20 \%$, o que deixaria de ser recomendado para o processo de ensilagem.

Vilela (1998) sugere buscar sua atenuação com adição de produtos ricos em matéria seca ou por meio de tratamentos que eliminem o excesso de umidade

Assim, objetivou-se, por meio desta pesquisa fornecer informações sobre a inclusão da batata diversa na forma de raspa com alto teor de matéria seca na ensilagem de capim-elefante em diferentes proporções.

\section{MATERIAL E MÉTODOS}

O trabalho foi conduzido nas dependências da Universidade José do Rosário Vellano- UNIFENAS em área do setor de forragicultura, na cidade de Alfenas, MG.

O delineamento experimental utilizado foi inteiramente casualizado, com cinco tratamentos e quatro repetições, utilizando 20 silos experimentais, onde foram feitas as silagens de capim-elefante conforme os tratamentos a seguir: $\mathrm{T}_{1}$ Capim-elefante; $\mathrm{T}_{2}$ Capimelefante $+7 \%$ de raspa de batata; $\mathrm{T}_{3}$ Capim-elefante + $14 \%$ de raspa de batata; $\mathrm{T}_{4}$ Capim-elefante $+21 \%$ de raspa de batata; $\mathrm{T}_{5}$ Capim-elefante $+28 \%$ de raspa de batata.

A análise bromatológica da raspa de batata, no momento da ensilagem está representada na Tabela 1 .

Para a obtenção da raspa de batata diversa desidratada, foi processada em picadeira para forragem, em seguida seca ao sol até alcançar teor de umidade entre 10 e $12 \%$; após esta etapa foi processada em moinho de martelo.

As plantas de capim-elefante foram picadas em partículas de 2 a $3 \mathrm{~cm}$ de tamanho. $\mathrm{O}$ material picado, após intensa homogeneização com a raspa de batata nos devidos níveis de inclusão, foi ensilado em silos de laboratório, confeccionados em tubos de "PVC" de $10 \mathrm{~cm}$ de diâmetro e $50 \mathrm{~cm}$ de comprimento. No fundo de cada silo, foi colocada uma quantidade conhecida de areia que ficava separada

Tabela 1 - Teores médios em porcentagem de matéria seca (MS), proteína bruta (PB), fibra em detergente neutro (FDN) e fibra em detergente ácido (FDA) da raspa de batata no momento da ensilagem de capim-elefante*

\begin{tabular}{lcccc}
\hline Aditivo & $\mathrm{MS}(\%)$ & $\mathrm{PB}(\%)$ & $\mathrm{FDN}(\%)$ & $\mathrm{FDA}(\%)$ \\
\hline $\begin{array}{l}\text { Raspa de } \\
\text { Batata }\end{array}$ & 86,13 & 12,36 & 10,21 & 7,61 \\
\hline
\end{tabular}

*Análises realizadas no Laboratório da UFLA. da silagem por uma tela de sombrite para evitar contaminação do material. Os silos foram mantidos fechados por uma período de 30 dias.

No momento da abertura dos silos o conteúdo superior e inferior de cada silo numa faixa aproximadamente dez centímetros foi descartado. O material central do silo foi homogeneizado em bandejas de plástico de onde foi retirado uma amostra, colocada e pesada em sacos de papel, levada para a estufa com circulação de ar forçada em temperaturas de $65^{\circ} \mathrm{C}$, por 72 horas.. As amostras présecas foram moídas em peneira de um milímetro, utilizando-se um moinho tipo Willey. No momento em que o silo foi aberto, dez gramas de silagem foram imediatamente utilizados para medida do $\mathrm{pH}$,

Foi determinada a perda de gases por meio da subtração do peso dos silos cheios, no momento da ensilagem, e antes de sua abertura. A perda de efluentes foi quantificada pela diferença de peso da areia contida no fundo do silo no momento de sua abertura e antes da ensilagem. As análises bromatológicas foram feitas no Laboratório de Análise Bromatológica da Faculdade de Medicina Veterinária da Universidade Estadual Paulista (FMVZ/UNESP) Botucatu-SP.

Foram feitas as determinações de porcentagens de matéria seca (MS) e proteína bruta (PB) conforme descrita por Horwtz (1975). Quanto à determinação de fibra em detergente neutro (FDN) e fibra em detergente ácido (FDA) seguiu-se a metodologia descrita por Goering \& Soest (1970). A digestibilidade "in vitro" da MS foi determinada de acordo com o método das duas etapas de Tilley e Terry, descrito por Silva (1981). A análise estatística dos dados foi realizada utilizando-se o programa SISVAR (FERREIRA, 2000). Para comparação das médias, foi realizada análise de regressão.

\section{RESULTADOS E DISCUSSÃO}

Para o teor de MS da silagem a regressão linear foi significativa e o coeficiente de determinação $\mathrm{R}^{2}=96,62 \%$ (Figura 1).

Foi observado um acréscimo de $0,54 \%$ no teor de MS para cada $1 \%$ de adição de raspa de batata, valor este semelhante aos 0,54 e $0,45 \%$ encontrados por Ferrari Júnior \& Lavezzo (2001), na adição de farelo de mandioca em silagens de capim elefante com níveis de 2; 4; 8 e $12 \%$ de farelo, respectivamente. Os maiores valores de MS observados nas silagens com aditivos de raspa de batata em relação a silagem pura de capim, provavelmente tenham ocorrido devido ao alto teor de MS $(86,13 \%)$ apresentado pela raspa de batata (Tabela1). 
Verificou-se que a porcentagem de matéria seca da silagem com a adição de $7 \%$ de raspa de batata pode ser considerada boa com valor de $25,38 \%$ de MS, conforme recomendado por Faria (1986) para silagens de capim-elefante.

No entanto, Nussio et al. (2004) relataram que valores de 30 a $35 \%$ de MS em silagem de milho propiciam altas ingestões de MS pelos animais.Neste estudo, esses valores foram observados nas silagens com adição de $14 \mathrm{e}$ $28 \%$ de raspa de batata.

Para os valores de $\mathrm{pH}$ verificou-se efeito linear $(\mathrm{P}<0,01)$ dos níveis de inclusão de raspa de batata e o coeficiente de determinação $\left(R^{2}=97,54 \%\right)$. Na Figura 2 estão os valores estimados de $\mathrm{pH}$ das silagens.

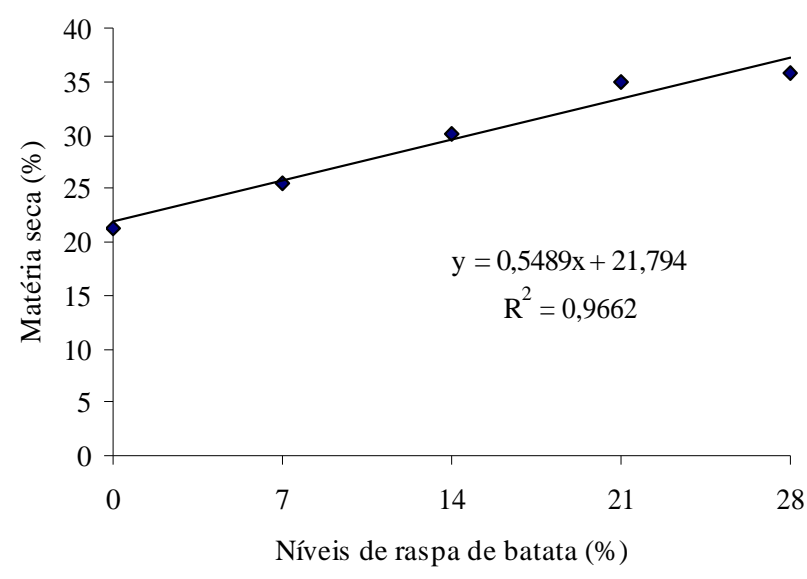

Figura 1 - Efeito dos níveis de raspa de batata diversa no teor médio de matéria seca da silagem de capim-elefante.

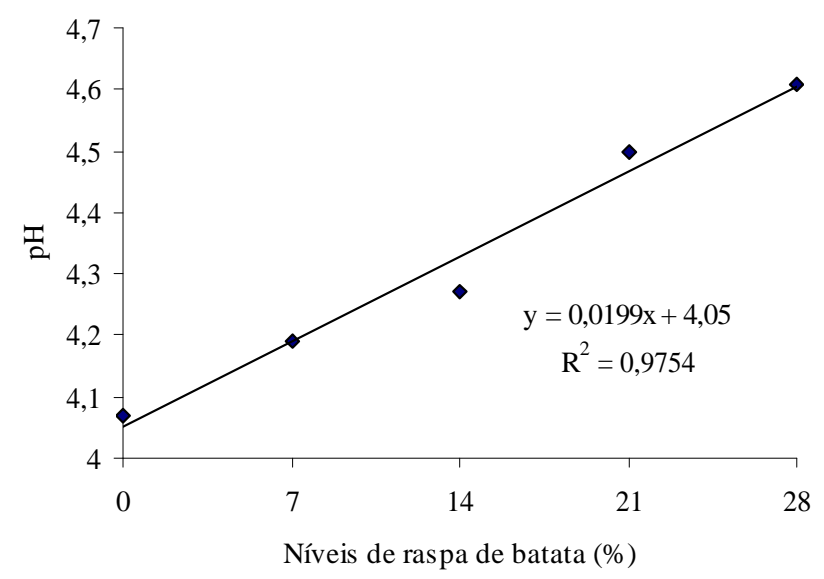

Figura 2 - Efeito dos níveis de raspa de batata "diversa" no valor médio de $\mathrm{pH}$ da silagem de capim-elefante.
Observou-se que, para cada $1 \%$ de adição de raspa, houve um aumento de $0,019 \%$ no $\mathrm{pH}$ das silagens de capim. Possivelmente esse aumento dos valores de $\mathrm{pH}$ possa ser explicado pelos constituintes das raspa de batata (amido e minerais), que são capazes de elevar o poder tampão dessas silagens. Segundo McDonald et al. (1991), a capacidade tampão da forragem é influenciada pela presença de ânions (sais de ácidos orgânicos , ortofosfatos, sulfatos, nitratos e cloretos), sendo a fração protéica a responsável por $20 \%$ da capacidade tampão.

Quanto à qualidade das silagens, medidas pelos valores de $\mathrm{pH}$, pode-se sugerir que os níveis de adição de 7 a $14 \%$ (4,19 a 4,27, respectivamente) de raspa de batata nas silagens de capim-elefante, proporcionaram bom padrão de conservação, se forem considerados os resultados de Silveira (1975). Este autor relatou que uma silagem de boa qualidade deve apresentar $\mathrm{pH}$ menor ou igual a 4,2.

Para produção de gases verificou-se que houve efeito significativo $(\mathrm{p}<0,01)$ para os tratamentos e coeficiente de determinação $r=22,9 \%$. Na Figura 3, observase valores de produção de gases, que comportou de forma quadrática atingindo seu valor mínimo quando adicionouse $14 \%$ de raspa de batata.

As perdas de gases nos tratamentos com 21 e $28 \%$ de raspa de batata foram maiores quando comparado com o tratamento com $14 \%$ de raspa. Isso possivelmente pode ser atribuído aos maiores teores de MS observados nessas silagens, proporcionando uma maior fermentação de carboidratos solúveis por bactérias heterofermentativas que são responsáveis pela produção de $\mathrm{CO}_{2}$ (MCDONALD et al., 1991) ocasionando aumento no $\mathrm{pH}$ de 4,20 (14\% de raspa de batata) para 4,50 (21\% de raspa de batata) e 4,61\% (28\% de raspa de batata).

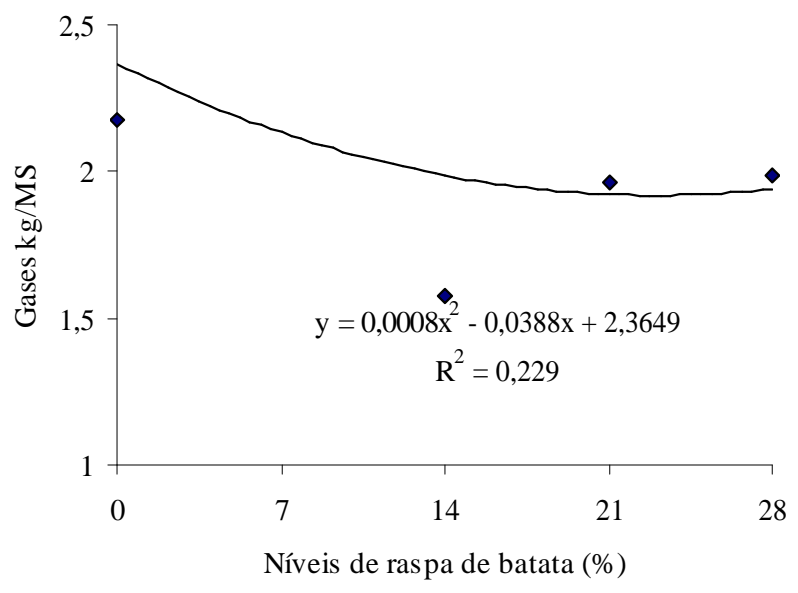

Figura 3 - Efeito dos níveis de raspa de batata diversa no valor médio de perdas de gases da silagem de capim-elefante. 
Segundo Jobim \& Gonçalves (2003), o pH final (ao redor de 4.0) após a fermentação é de grande importância para impedir o crescimento de bactérias do gênero Clostridium e inibição da ação de fungos responsáveis pela perda de gases.

Para os resultados referentes à perda de efluentes houve efeito significativo $(\mathrm{P}<0,01)$ para os tratamentos, observando-se uma regressão linear com o coeficiente de determinação $R^{2}=75,7 \%$ (Figura 4).

A diminuição na perda de efluente a partir da adição de $14 \%$ de raspa de batata pode ser explicada pelo teor de MS, pois quando esta quantidade de raspa de batata foi adicionada à silagem, observou-se um teor de 30,03\% MS na silagem produzida.

Loures (2000), ensilando capim-elefante c.v. Cameron com 13 e $25 \%$ de MS, observou que não houve produção de efluentes naquele capim ensilado com maior teor de MS, enquanto que na silagem do capim com 13\% de MS observou-se perdas significativas de MS e nutrientes por meio do efluente.

Com a inclusão de 21 e $28 \%$ de raspa de batata, as médias observadas para perdas de efluentes 1,56 e 1,58 $\mathrm{kg} / \mathrm{ton} \mathrm{MV}$, respectivamente, foram semelhantes à média quando foi adicionada $14 \%$ de raspa de batata $(1,56 \mathrm{~kg} / \mathrm{ton}$ MV). Isso provavelmente possa ser explicado pelo fato de haver uma estabilidade no teor de MS que possa ter prejudicado a produção de efluente (PEREIRA \& BERNARDINO, 2004).

Para proteína bruta a regressão quadrática foi significativa $(\mathrm{P}<0,01)$ e o coeficiente de determinação $\mathrm{R}^{2}=$ 99,3\%. A variação das porcentagens de proteína bruta está representada pela equação de regressão na Figura 5. Pelos resultados, observa-se um aumento na porcentagem de proteína bruta na matéria seca até aproximadamente $21 \%$ de adição de raspa na silagem de capim. No entanto, valores de adição acima disso, proporcionam uma ligeira redução na porcentagem de $\mathrm{PB}$.

As silagens constituídas apenas de capim apresentaram porcentagem de proteína de 6,32\%, significativamente inferior ao valor observado nas silagens aditivadas com raspa de batata. Esta baixa porcentagem de proteína bruta, observada na silagem de capim-elefante, pode ser atribuída, em parte, à perda de nutriente no efluente produzido e em parte, à secagem das amostras da silagem em estufa, o que ocasionaria a volatilização do nitrogênio amoniacal de acordo com McDonald et al. (1991).

Neste estudo foram encontradas porcentagens de PB superiores às encontradas por Ferrari Júnior \& Lavezzo (2001), que obtiveram valores de 7,49 e 6,42\% para os teores de proteína bruta das silagens de capim-elefante com $2 \%$ e $12 \%$ de farelo de mandioca, respectivamente.

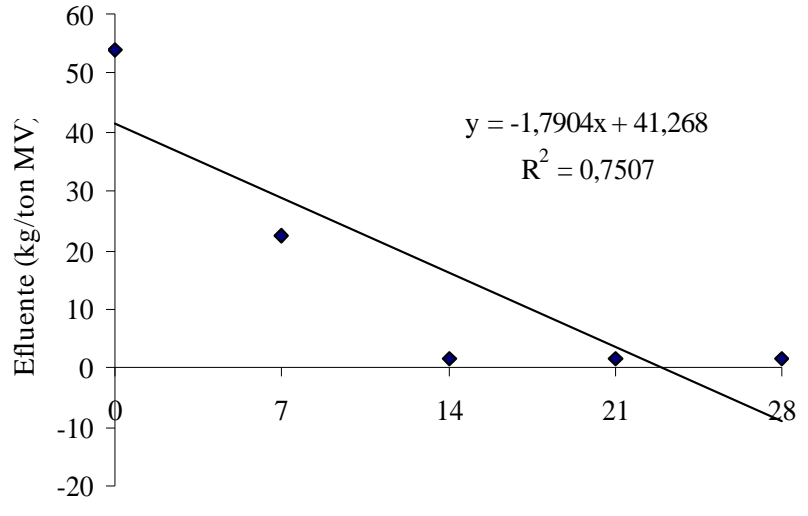

Níveis de raspa de batata (\%)

Figura 4-Efeito dos níveis de raspa de batata diversa no valor médio de perdas de efluentes da silagem de capim-elefante.

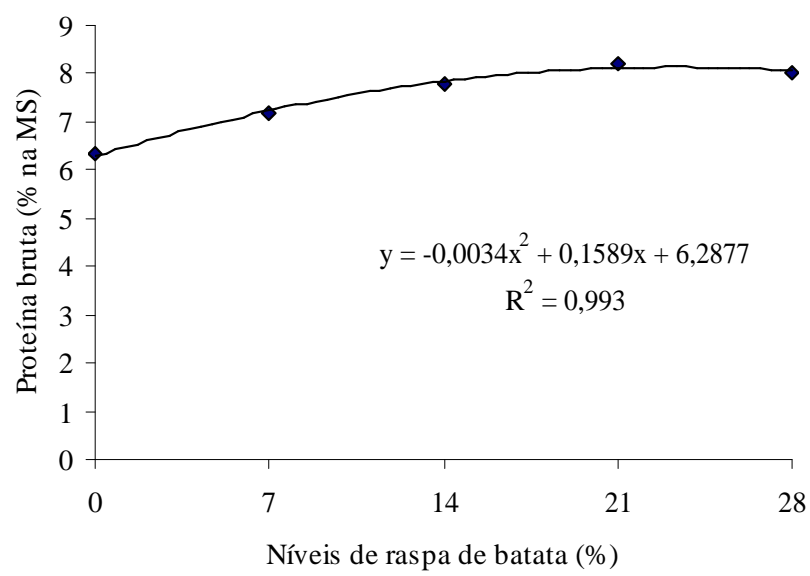

Figura 5 -Efeito dos níveis de raspa de batata "diversa" no valor médio de proteína bruta da silagem de capim-elefante.

Os dados observados neste estudo com adição de raspa foram maiores que o limite mínimo de $7 \%$ relatado por Milford \& Mingon (1966), abaixo do qual há limitação no consumo de forragens tropicais.

Para os valores de FDN, a regressão linear foi significativa $(\mathrm{P}<0,01)$ e o valor do coeficiente de determinação $R^{2}=97,59 \%$ (Figura 6).

Observou-se uma redução média de $1,41 \%$ de FDN para cada $1 \%$ de acréscimo de raspa de batata ao capimelefante. Resultado que pode ser explicado pelo menor teor de FDN da raspa de batata em relação ao capim-elefante, e principalmente pela menor produção de efluente observada (Figura 4), conseqüentemente ocorrendo uma menor perda de MS nas silagens com raspa de batata. 


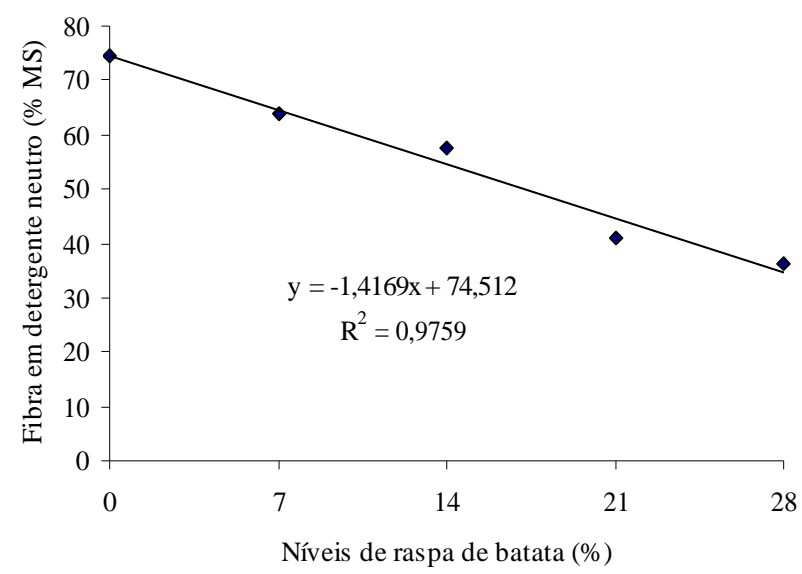

Figura 6 - Efeito dos níveis de raspa de batata "diversa" no valor médio de fibra em detergente neutro da silagem de capim-elefante.

Souza et al. (2003) obtiveram porcentagem de FDN de $61,74 \%$ em silagens de capim-elefante com $34,8 \%$ de inclusão de casca de café. Ferrari Júnior \& Lavezzo (2001) observaram porcentagem de FDN 60,37\% em silagens de capim-elefante $12 \%$ de farelo de mandioca. Neste estudo foram encontrados resultados semelhantes quando adicionou-se $14 \%$ de raspa de batata $(57,65 \%)$.

Para os valores de FDA nas silagens de capimelefante, a regressão linear foi significativa e o valor do coeficiente de determinação é $\mathrm{R}^{2}=89,54 \%$ (Figura 7).

Neste estudo, foi observada uma redução de 1,04\% nos valores de FDA para cada $1 \%$ de acréscimo de raspa de batata na silagem de capim-elefante. Estes resultados possivelmente possam ser explicados pelos mesmos argumentos utilizados para redução de FDN, discutidos no item anterior.

Neste estudo foram encontradas porcentagens inferiores $(24,41 \%$ com $28 \%$ de raspa de batata) das encontradas por Souza et al. (2003), que obtiveram porcentagem $44,12 \%$ em silagens de capim-elefante com $34,8 \%$ de casca de café. Ferrari Júnior \& Lavezzo (2001) obtiveram porcentagem de FDA de 41,04\% em silagens de capim-elefante com $12 \%$ de farelo de mandioca, porcentagem esta semelhante à encontrada neste estudo com a adição de $7 \%(38,45 \%)$ de raspa de batata.

Referentes à digestibilidade in vitro da matéria seca, houve efeito significativo $(\mathrm{P}<0,01)$. Para essa característica, a regressão linear e o coeficiente de determinação $\mathrm{R}^{2}=91,65 \%$, (Figura 8 ).

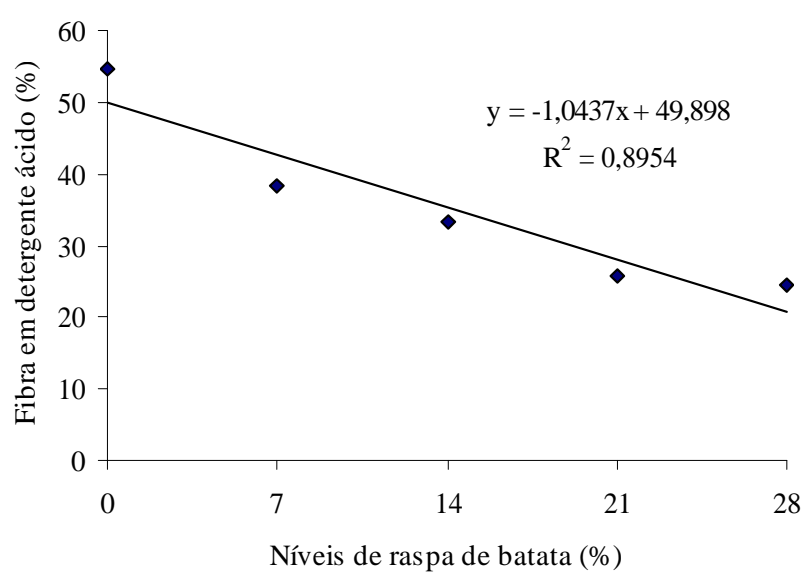

Figura 7 - Efeito dos níveis de raspa de batata diversa no valor médio de fibra em detergente ácido da silagem de capim-elefante.

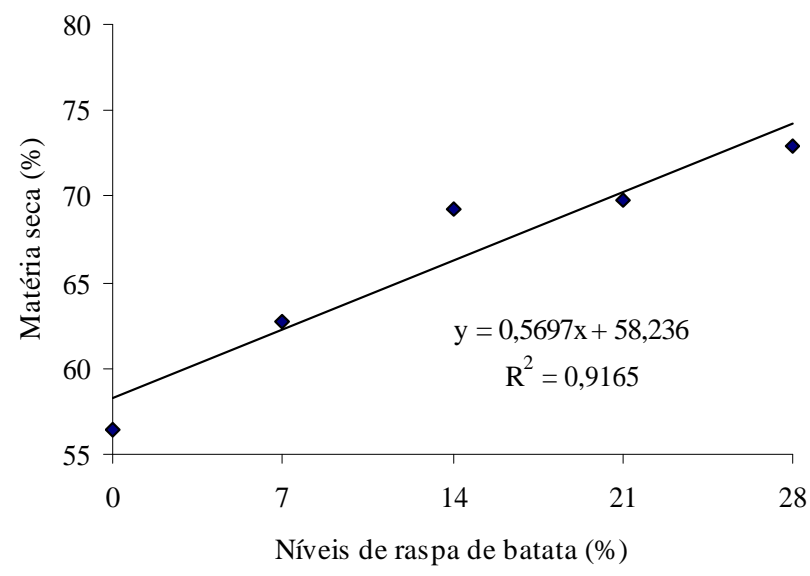

Figura 8 - Efeito dos níveis de raspa de batata diversa no valor médio da digestibilidade in vitro da matéria seca da silagem de capim-elefante.

Valores maiores de DIVMS observados para os tratamentos com raspa de batata em relação à testemunha (capim sem raspa), podem ser devido à concentração de nutrientes na raspa de batata, afetando positivamente nas silagens. Esse comportamento já era esperado e concorda com os resultados observados nos teores de FDN e FDA, citados nos itens anteriores, demonstrando uma relação linear positiva entre essas variáveis.

Os resultados de DIVMS obtidos neste estudo com menores níveis de inclusão (7\%) de raspa de batata $(62,68 \%)$ foram superiores aos observados por Rezende et al. (2002), (60\% DIVMS), em pesquisa com associação de $23 \%$ de 
planta de girassol na silagem de capim-elefante, e também superiores aos verificados por Evangelista et al. (1987), os quais estudaram o uso de $6 \%$ de MDPS na forma de aditivo para produção de silagens de capim-elefante, tendo eles verificado uma DIVMS de 52\% e semelhante ao encontrado por Sousa et al. (2003) em pesquisa realizada com níveis de casca de café em silagens de capim-elefante com médias de 64,$48 ; 63,24 ; 62,00 ; 60,77$ e $59,53 \%$ para os níveis de 0 ; 8,$7 ; 17,4 ; 26,1$ e $34,8 \%$ na mesma ordem.

\section{CONCLUSÕES}

Batata "diversa" na forma de raspa de batata moída adicionada à planta de capim-elefante no momento da ensilagem nos níveis de 7 e $14 \%$ produz silagens de qualidade satisfatória, melhorando as características químicas e nutricionais.

Recomendam-se ensaios de produção com bovinos de leite e corte para comprovar os resultados observados.

\section{REFERÊNCIAS BIBLIOGRÁFICAS}

EVANGELISTA, A. R. et al. Uso do milho desintegrado com palha e sabugo na forma de aditivo para produção de silagem de capim-elefante (Pennisetum purpureum Shum.). In: REUNIÃO ANUAL DA SOCIEDADE BRASILEIRA DE ZOOTECNIA, 24., 1987, Brasília, DF. Anais... Brasília, DF: Sociedade Brasileira de Zootecnia, 1987. p. 190.

FARIA, V. P. Técnicas de produção de silagens. In: CONGRESSO BRASILEIRO DE PASTAGENS, 1., 1986, Piracicaba. Anais... Piracicaba: Fundação de Estudos Agrários “Luiz de Queiroz”, 1986. p. 119-144.

FERRARI JÚNIOR, E.; LAVEZZO, W. Qualidade da silagem de capim-elefante (Pennisetum purpureum Schum.) emurchecido ou acrescido de farelo de mandioca. Revista Brasileira de Zootecnia, Viçosa, v. 30, n. 5, p. 1424-1431, 2001.

\section{FERREIRA, D. F. SISVAR. Lavras: UFLA, 2000.}

GOERING, H. K.; SOEST, P. J. van. Forage fiber analysis: apparatus reagents, procedures, and some applications. Agricultural Handbook, Washington, 1970.

HORWTZ, W. (Ed.). Official methods of analyses of association of the official analytical chemist. 17. ed. Washington: AOAC, 1975. 1094 p.

JOBIM, C. C.; GONÇALVES, G. D. Microbiologia de forragens conservadas. In: SIMPÓSIO SOBRE
VOLUMOSOS NA PRODUÇÃO DE RUMINANTES, 1., 2003, Jaboticabal. Anais... Jaboticabal: FUNESP, 2003. p. 126.

LAVEZZO, W. Silagem de capim-elefante. Informe Agropecuário, Belo Horizonte, v. 11, n. 132, p. 50-57, dez. 1985.

LOURES, D. R. S. Características do efluente e composição químico-bromatológica da silagem sob níveis de compactação e de umidade do capim-elefante (Pennisetum purpureum Schum.), cv. Cameron. 2000. 65 f. Dissertação (Mestrado em Zootecnia) - Universidade Federal de Viçosa, Viçosa, 2000.

McDONALD, P.; HENDERSON, A. R.; HERON, S. J. E. The biochemistry of silage. 2. ed. Marlow: Calcombe, 1991. $340 \mathrm{p}$.

MILFORD, D.; MINGON, D. J. Intake of tropical pasture species. In: CONGRESSO INTERNACIONAL DE PASTAGENS, 9., 1965, São Paulo. Anais... São Paulo: Secretaria de Agricultura-Departamento de Produção Animal, 1966. v. 1, p. 15-22.

NUSSIO, L. G.; PAZIANI, S. F.; NUSSIO, C. M. B.Ensilagem de capins tropicais. In: REUNIÃO ANUAL DA SOCIEDADE BRASILEIRA DE ZOOTECNIA, 39., 2002, Recife. Anais... Recife: SBZ, 2004. p. 60-99.

PEREIRA, O. G.; BERNARDINO, F. S. Controle de efluentes na produção de silagem. In: SIMPÓSIO SOBRE MANEJO ESTRATÉGICO DA PASTAGEM, 2., 2004, Viçosa. Anais... Viçosa: UFV, 2004. p. 510-545.

REZENDE, A. V.; EVANGELISTA, A. R.; BARCELOS, A. F.; SIQUEIRA, G. R. Efeito da Mistura da Planta de Girassol (Helianthus annuus L.) durante a Ensilagem do CapimElefante (Pennisetum Purpureun Shum.) no valor nutritivo da silagem. In: REUNIÃO ANUAL DA SOCIEDADE BRASILEIRA DE ZOOTECNIA, 39., 2002, Viçosa. Anais... Viçosa: SBZ, 2002. p. 1938-1943.

SILVA, D. J. Análise de alimentos: métodos químicos e biológicos. Viçosa: UFV, 1981. 160 p.

SILVEIRA, A. C. Técnicas para produção de silagens. In: SIMPÓSIO SOBRE MANEJO DE PASTAGENS, 2., 1975, Piracicaba. Anais... Piracicaba: ESALQ, 1975. p. 156-180. 
SOUZA, A. L.; BERNARDINO, F. S.; GARCIA, R. Valor nutritivo de silagem de capim-elefante (Pennisetum Purpureun Shum.) com diferentes níveis de casca de café. Revista da Sociedade Brasileira de Zootecnia, Viçosa, v. 32, n. 4, p. 828-833, 2003.
VILELA, D. Aditivos para silagens de plantas de clima tropical. In: SIMPÓSIO SOBRE ADITIVOS NA PRODUÇÃO DE RUMINANTES E NÃO RUMINANTES, 1998, Botucatu. Anais... Botucatu: SBZ, 1998. p. 53-72. 